
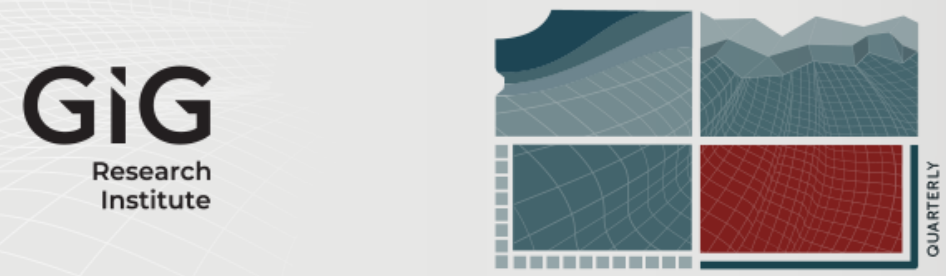

JOURNAL

OF

SUSTAINABLE

MINING

Volume 20 | Issue 3

Article 4

2021

\title{
The factors impacting the incorporation of the Sustainable Development Goals into Raw Materials Engineering Curricula
}

Author(s) ORCID Identifier:

Dimitris Damigos (D) 0000-0003-0142-7156

George Valakas (D) 0000-0003-0142-7156

Anna Gaki (iD 0000-0001-6452-5680

Katerina Adam (iD) 0000-0002-4261-5711

Follow this and additional works at: https://jsm.gig.eu/journal-of-sustainable-mining

Part of the Explosives Engineering Commons, Oil, Gas, and Energy Commons, and the Sustainability Commons

\section{Recommended Citation}

Damigos, Dimitris; Valakas, George; Gaki, Anna; and Adam, Katerina (2021) "The factors impacting the incorporation of the Sustainable Development Goals into Raw Materials Engineering Curricula," Journal of Sustainable Mining: Vol. 20 : Iss. 3 , Article 4.

Available at: https://doi.org/10.46873/2300-3960.1320

This Research Article is brought to you for free and open access by Journal of Sustainable Mining. It has been accepted for inclusion in Journal of Sustainable Mining by an authorized editor of Journal of Sustainable Mining. 


\title{
The factors impacting the incorporation of the Sustainable Development Goals into Raw Materials Engineering Curricula
}

\begin{abstract}
It is widely recognised and acknowledged that the mining industry, if properly operating and managed, has the potential to positively contribute to "The 2030 Agenda for Sustainable Development". In this direction, the Raw Materials (RM) engineering education possesses a crucial role, given the need to instil in tomorrow's mining engineers the sustainability principles. This paper explores the educational needs of the Greek RM sector and the factors constituting the RM whole value chain SDGs-education-innovation eco-system. The research follows a two-stage focus group approach. First, the perceptions, opinions and beliefs of invited stakeholders were explored in the context of semi-structured interviews. Then, the stakeholders were requested to identify the main components of the RM-SDGs-education-innovation ecosystem using the Fuzzy Cognitive Maps (FCMs) method. According to the results, the incorporation of the sustainable development (SD) principles in the educational process is considered a priority. However, only a few courses provide the basics of SD principles in the Greek RM engineering curricula, so far. Further, the FCM approach offered the means to explore the factors identified by the stakeholders as pivotal in the RM-SDGs-education-innovation system and the interactions between them.
\end{abstract}

\section{Keywords}

sustainable development goals, mining and metallurgical engineering education for sustainable development, engineering curriculum, fuzzy cognitive mapping

\section{Creative Commons License}

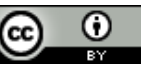

This work is licensed under a Creative Commons Attribution 4.0 License. 


\title{
The factors impacting the incorporation of the sustainable development goals into raw materials engineering curricula
}

\author{
Dimitris Damigos*, George Valakas, Anna Gaki, Katerina Adam
}

National Technical University of Athens, School of Mining and Metallurgical Engineering, GreeceAvailable online 19 September 2021

\begin{abstract}
It is widely recognised and acknowledged that the mining industry, if properly operating and managed, has the potential to positively contribute to "The 2030 Agenda for Sustainable Development". In this direction, the Raw Materials (RM) engineering education possesses a crucial role, given the need to instil in tomorrow's mining engineers the sustainability principles. This paper explores the educational needs of the Greek RM sector and the factors constituting the RM whole value chain SDGs-education-innovation eco-system. The research follows a two-stage focus group approach. First, the perceptions, opinions and beliefs of invited stakeholders were explored in the context of semistructured interviews. Then, the stakeholders were requested to identify the main components of the RM-SDGs-education-innovation eco-system using the Fuzzy Cognitive Maps (FCMs) method. According to the results, the incorporation of the sustainable development (SD) principles in the educational process is considered a priority. However, only a few courses provide the basics of SD principles in the Greek RM engineering curricula, so far. Further, the FCM approach offered the means to explore the factors identified by the stakeholders as pivotal in the RM-SDGs-educationinnovation system and the interactions between them.
\end{abstract}

Keywords: sustainable development goals, mining and metallurgical engineering education for sustainable development, engineering curriculum, fuzzy cognitive mapping

\section{Introduction}

I n September 2015, at the UN Sustainable Development Summit in New York, all United Nations Member States adopted the outcome document "The 2030 Agenda for Sustainable Development" [1]. The Agenda, building on the Millennium Development Goals (MDGs) which were launched in 2000, involves 17 Sustainable Development Goals (SDGs) and 169 targets to be fulfilled over the next fifteen years in areas of critical importance for humanity and the planet [1]. The SDGs, contrary to the MDGs, apply to all countries and address ecological sustainability challenges besides economic and social goals [2] in the sustainability three pillars, i.e. economic, social and environmental, in a balanced and integrated manner [1]. Nevertheless, the SDGs have been criticized among others for being too ambitious, relatively vague, based on weak institutional arrangements, inconsistent - particularly between the socio-economic and the environmental goals, difficult to quantify and monitor and nonbinding from a legal perspective [2-7]. Besides the challenges, however, it is argued that the SDGs are universal (i.e. they do not distinguish developed and developing countries in terms of sustainability) and allow a more logical and practical integration of the three dimensions of sustainable development $[8,9]$, and this makes the SDGs a novel type of governance and "... one of the most intriguing new global initiatives in the area of sustainable development and environmental policy ..." (p. 29) [8].

The implementation of the SDGs is a challenge for all economic activities and mining is not an exception as it is directly linked to a large number - if not all - of the 17 SDGs [10,11]. On the one hand,

Received 23 June 2021; revised 2 August 2021; accepted 9 August 2021.

Available online 19 September 2021

* Corresponding author.

E-mail address: damigos@metal.ntua.gr (D. Damigos). 
mining has the potential to create employment, foster economic development in local, regional and national scale, generate state revenues through taxes and royalties, improve transport, communication and other infrastructure, offer educational opportunities, etc. However, if not conducted properly, mining can result in long-lasting irreversible environmental problems, exacerbate social and economic inequality, trigger conflicts and contribute to political corruption [11-13]. It is thus evident that the mining industry is capable of contributing both positively and negatively to the SDGs achievement [14]. In recent decades, the industry has made significant advances in improving the way it manages its potential environmental and social impacts in the context of company-community conflict minimization $[13,15]$. But, for the RM industry to be the cornerstone of sustainable development, the RM engineering curricula need to instil in today's students and tomorrow's professionals the sustainability principles.

Within this context, a two-year integrated Regional Innovation Scheme (RIS) project entitled "Enhancing the skills of ESEE RM students towards the achievement of SDGs - EnActSDGs" was initiated in 2020. The project is funded by the EIT (European Institute of Innovation and Technology) Raw Materials and focuses on RM students from three East and Southeast Europe (ESEE) countries, namely Greece, Poland and Slovakia. It aspires to promote, in a multidisciplinary and multicultural environment, innovation, entrepreneurship and effective performance and strengthen the skills and competencies of RM university students towards the achievement of the SDGs. More specifically, the project team includes three ESEE beneficiary universities from Poland (AGH University of Science and Technology - AGH), Greece (National Technical University of Athens - NTUA, and Slovakia (Technical University of Kosice - TUKE), three innovation providers from Austria (Montanuniversität Leoben), Germany (Technische Universität Bergakademie Freiberg), and Italy (Unitrento and Hub Innovazione Trentino) and an industrial partner from Greece (MYTILINEOS). From the beneficiary universities, the curricula of three RM engineering departments were examined and more specifically the Faculty of Mining and Geoengineering of AGH in Poland, the School of Mining and Metallurgical Engineering of NTUA in Greece and the Faculty of Mining, Ecology, Process Control and Geotechnologies of TUKE in Slovakia. The scope of EnActSDGs is to provide a pathway that will ensure the incorporation of the SDGs in the curricula of the RM engineering schools beneficiary universities and establish a sustainable network and eco-system between beneficiary and innovation provider universities, research institutes and the RM industry [16]. In this direction, the structure of the curricula of the RM schools in the three ESEE beneficiary universities is evaluated regarding the incorporation of SD principles.

Based on the research conducted within the EnAct-SDGs project, this paper focuses on the identification of the educational needs in the Greek RM engineering studies and analyses the interviews conducted with Greek stakeholders following a twostage focus group approach. First, the stakeholders were invited to discuss the educational needs and challenges for the achievement of SDGs in the RM sector through semi-structured interviews. Then, they were requested to identify the main components of the RM whole value chain SDGs-education-innovation eco-system using a widely used method employed for studying the structure and behaviour of complex systems, namely the Fuzzy Cognitive Maps (FCMs). To the authors' best knowledge, this is the first study that uses this approach to examine the factors constituting the RM whole value chain SDGs-education-innovation ecosystem and their interactions.

The rest of the paper is structured, as follows. Section 2 provides a brief literature review on the role of engineering education in sustainable development with a focus on RM curricula. Section 3 describes the methodological approach. Section 4 analyses the results of the survey. Finally, Section 5 concludes with the main findings and provides recommendations for future research.

\section{Literature review}

The role of education in sustainable development was initially set out in the Tbilisi Declaration at the closure of the world's first intergovernmental conference on environmental education, which was organised by UNESCO in cooperation with the U.N. Environment Programme (UNEP) [17]. The principles and the programme areas of environmental education were detailed in Chapter 36 Promoting Education, Public Awareness and Training of the Agenda 21 [18]. In 2002, the U.N. General Assembly adopted the Resolution 57/254 to designate the decade 2005-2014 as the "United Nations Decade of Education for Sustainable Development (UNDESD)" [19]. Also in 2002, the World Federation of Engineering Organisations (WFEO) noted that engineering education for sustainable development (EESD) encourages engineers to play “... an important role in planning and building projects 
that preserve natural resources, are cost-efficient and support human and natural environments ..." (p. 4) [20]. The need to incorporate sustainability into the engineering curricula was further highlighted in UNESCO's report on Engineering Initiative [21]. However, “... a large-scale transition to producing engineering graduates with the knowledge and skills to meet the changing needs of the profession over the coming ..." (p. 5) had not happened till 2010 [22]. This was, at least partially, attributed to the fact that the process for updating engineering curriculum using standard methods might take over $15-20$ years, creating the so-called time lag dilemma for engineering departments [23].

Over the last ten years, things have changed. As mentioned by Kelly [24], “... sustainability is explicitly included in the WFEO Model Code of Ethics under Canon 4 protection of the natural and built environment. The WFEO Model Code of Practice for Sustainable Development and Environmental Stewardship provides a comprehensive approach to sustainability in engineering practice ..." (p. 1). Further, he mentions that graduates from engineering programs accredited under the International Engineering Alliance (IEA) Washington Accord “... can be expected to have an understanding of sustainability in the context of engineering practice in their field ..." (p. 2). This shift is also apparent in the recent scientific literature [25-40].

Following the same trend, many RM schools and departments worldwide have incorporated the concept of sustainable development in their curricula, in response to the requirements of accreditation of their programs and the challenges of the changing environment for the mining industry. For instance, in 2005, in the Mining School of Oviedo, Spain, a minimum compulsory formation in the subject environmental engineering and technology was adopted and obligatory taught in the third year of studies [41]. To integrate sustainable development into mining engineering, the Mining Engineering Department at the University of British Columbia, Canada, established the Sustainability Working Group (SWG), bringing together a diverse array of disciplines from academia, industry, government, NGOs and mining communities. The SWG offered two undergraduate courses (i.e. sustainability and professional engineering practice) and planned a new course on aboriginal peoples and engineering [42]. In 2007, the Robert M. Buchan Department of Mining at Queen's University, Canada, introduced, as a first step, a stand-alone course in mining and sustainability. The Department continued its efforts to integrate environmental and cultural issues into technical courses as a norm [43]. Also, MSc education programs dedicated to mineral resources and sustainability were developed, which were supported, on several occasions, by initiatives like the European Institute of Innovation and Technology (EIT) and EIT Raw Materials, e.g. OpenYourMine, geomatics for mineral resource management and entrepreneurship, innovation and technology integration in mining [44]. Nevertheless, there are challenges and barriers towards incorporating sustainability principles in RM curricula, like in other engineering disciplines. In general, some curricula offer coverage of sustainability issues in a specific, i.e. stand-alone, course, while others involve sustainability in existing courses, tailored to the nature of each course [45-47].

\section{Materials and methods}

The successful implementation of the SD principles requires the involvement of all stakeholders of the RM sector $[48,49]$. Thus, towards identifying the factors interacting in the RM whole value chain SDGs-education-innovation system, information was collected from focus group interviews following a two-stage approach, as mentioned. The focus group comprised of five stakeholder representatives from academia (students and academic staff), industry and professionals, taking into account that the guidance on group size is between a minimum of four and a maximum of twelve participants [50-52]. Students' engagement is critical for achieving sustainable changes in the curriculum of HEIs not only because students need to be aware of EESD benefits but also because the cooperation between students and academic staff in forming the curricula can enhance engagement and motivation [53] and lead to improved assessment performance [54]. The academic staff has a crucial role in the diffusion of SD principles, as the staff awareness of SD affects the pedagogical techniques used to activate and motivate the students. The engagement with the RM industry and professionals is also an essential organisational issue for universities to consider when integrating SD within engineering education [55]. The industry is the main critical stakeholder applying the SD principles, while engineering students consider the industrial experience highly valuable [56].

The perceptions, opinions and beliefs of representatives of the main stakeholders were explored in the context of online focus group discussions, due to social distancing measures adopted to control the spread of COVID-19. At the first stage, the participants expressed their opinions and beliefs 
regarding the educational needs and challenges for the achievement of SDGs in the RM sector through semi-structured interviews. In this context, ten specific questions were prepared (see Appendix I) considering the priority action areas established by the Global Action Programme on ESD [57]. The research questions were framed by the SD awareness, opinions and perceptions of the research target groups, the role of stakeholder partnerships, the benefits of internships and the assessment of curriculum structure and content according to the SD principles.

At the second stage, the participants were asked, using the Fuzzy Cognitive Maps (FCMs) approach, to identify the main components of the RM whole value chain SDGs-education-innovation and their interrelationships. The FCMs is a popular method used for studying the structure and behaviour of complex systems introduced by [58]. FCMs present a high ability to demonstrate complexity, are not time- and resource-intensive to develop and are considered generally easy to instruct by interviewers and understand by stakeholders [59]. FCMs have gained considerable interest in a wide range of fields, e.g. environmental management, energy planning, political and social sciences, marketing, engineering, medicine and many others [60-69]. FCMs approach has also been used in educational studies. For instance, Cole and Persichitte [70] examined the potential use of FCMs in educational organization settings as means to facilitate conceptual change for educational technologists. Laureano-Cruces et al. [71] used a FCM to represent the conduct of an expert that evaluates the results of the teaching-learning process within a reactive learning environment. Pacheco et al. [72] used FCMs for the study, plan and formative assessment of the teaching/learning environment. Tsadiras and Stamatis [73] examined the interactions and causal relations among various key networked learning factors both statically and dynamically based on the knowledge extracted by a domain expert. Yesil et al. [74] employed the FCM approach to model the control engineering educational critical success factors. Gordaliza and Flórez [75] explored the possibilities offered by FCMs in the field of science education. Dias et al. [76] examined whether the structural characteristics of an FCM can efficiently model the way learning management systems can support online learning environments at higher education institutions. Mourhir and Kissani [77] built FCMs by academic staff and students to assess whether soft skills are introduced, reinforced or emphasized in engineering curricula.

FCMs are signed fuzzy digraphs which consist of nodes $C_{i}, i=1 \ldots N$, where $N$ is the total number of nodes and connecting edges. More explicitly, the nodes represent the components (also known as concepts or factors) of the system under investigation. The connecting edges represent the causal relationships among the components. Each interconnection between two concepts $C_{i}$ and $C_{j}$ has a weight, a directed edge $W_{i j}$, which is similar to the strength of the causal links between $C_{i}$ and $C_{j}$ and takes values in the interval $[-1,1]$. The direction of causality indicates whether the concept $C_{i}$ causes the concept $C_{j}$ or vice versa. $W_{i j}$ can be:

- less than 0 indicating a negative effect of the one concept to the other (i.e. when the value of $C_{i}$ increases, the value of $C_{j}$ decreases)

- greater than 0 indicating a positive effect (i.e. when the value of $C_{i}$ increases, the value of $C_{j}$ increases, as well)

- equal to 0 (indicating no causal relation between the concepts)

The structural properties of FCMs can be analysed based on graph theory and networks analysis indices such as the number of concepts and connections between them, the complexity index, the indegree and outdegree values, etc. [58,68,78,79].

Besides the static analysis, FCMs can be used to model the dynamic evolution of the concepts' interplay and make inferences about causation from any given set of initial conditions that may represent a policy or program. In this sense, "what-if" scenarios can be investigated, based on the activation levels of concepts at the final state and/or changes in the activation levels throughout the simulation concerning either all concepts or a subset of concepts of interest $[69,79]$. The simulation aims mainly to identify the general pattern of the system's behaviour via the achieved values of the FCM's concepts and not to produce exact quantitative values [69].

The input vector is 1 by $n$, the FCM adjacency matrix is $n \times n$, and the output is 1 by $n$ [69]. The value $A_{i}$ of each concept $C_{i}$ in a moment $t+1$ is calculated by the product of the value $A_{j}$ of the cause node $C_{j}$ in precedent moment $t$ and the value of the cause-effect link $w_{i j}$, as follows in a memoryless process $[80,81]$ :

$A_{i}^{(k+1)}=f\left(\sum_{\substack{j \neq i \\ j=1}}^{N} A_{j}^{(k)} W_{j i}\right)$

where $A_{i}^{(k+1)}$ is the value of concept $C_{i}$ at simulation step $k+1, A_{i}^{(k)}$ is the value of concept $C_{j}$ at step $k$, $W_{j i}$ is the weight of the interconnection between 
concept $C_{j}$ and concept $C_{i}$ and $f$ is an activation threshold function (e.g. a sigmoidal function in this case, which gives values of concepts in the range $[0,1])$.

The algorithmic procedure consists of five steps [69], which is repeated until the minimum error difference among the subsequent concepts reaches a predefined level.

\section{Results}

\subsection{Semi-structured interview findings}

\subsubsection{Integrating sustainability thinking into the traditional engineering curriculum}

All the participants agreed that it is quite important to integrate sustainability thinking into the traditional engineering curriculum. The representatives from industry and professionals highlighted that it is a prerequisite for RM engineers to be familiar with the SD principles and that this knowledge should be provided by the RM curricula. The representatives from academia recognised the need to enhance the knowledge offered by the existing curriculum with regards to sustainability [82]. So far, the emphasis of the existing curriculum is placed on technological issues (e.g. reuse and recycling of raw materials), ignoring or underestimating the role of important SDGs, such as decent work and economic growth, responsible consumption and production, reduced inequality, etc.

The focus group participants were also asked to express their views on how the SDGs could be actively incorporated and promoted through the curriculum. More explicitly, they were asked to comment whether they considered that SDGs should be taught through all (or as many as possible) the courses of the curriculum (even purely engineering ones) or as a separate course on its own. All the participants agreed that if the only modification made would be a stand-alone course this would be ineffective because SD is a multidimensional topic embracing technical, financial, social, environmental and other areas. In the participants' opinion, what is needed is a compulsory course that would provide the students with the basic knowledge about SD and a "horizontal inclusion" of the SD principles across all technical and non-technical courses. Further, practically all participants underlined the important role of faculty members and the need to be at least familiar with the principles of SD to embed them into their courses.
Finally, the participants discussed the importance of internship towards gaining a better understanding of the role of SDGs for the RM sector. All the participants stressed the role of internship not only in the career path of RM students but also - and mainly to - the implementation of SDGs by the RM sector. The students, through internships, get an idea of how the RM sector deals with the SDGs and start thinking about their role, as engineers, in improving the sustainability performance of the sector. Thus, internship serves as a bridge between the university and the industry because it provides the students with the opportunity to apply the knowledge they have gained at the university in real-life cases. However, they also mentioned that the existing duration of internships offered by the School of Mining and Metallurgical Engineering of NTUA (i.e. one month) is simply not enough. To their opinion, the internship for RM engineering studies should last at least two and optimally six months.

\subsubsection{The role of $R M$ graduates in the context of SDGs implementation}

Due to the multidimensional nature of SD, a series of questions were addressed to the focus group participants towards exploring the role of RM graduates in the implementation of the SDGs in the RM sector. First, the participants were asked to comment on the importance of soft skills for RM graduates. All the participants replied that soft skills possess a major role in the implementation of the SDGs. RM engineers must have the ability not only to find the best solution from an environmental, technical and economic perspective but also to effectively communicate this solution to different stakeholder groups. As was characteristically mentioned, even the best solution is condemned to fail if it's not supported by an effective communication strategy. Moreover, it was referred that social skills are necessary because they provide RM engineers with the ability to understand and to interpret the meaning of SDGs. The participants, and especially those coming from academia, argued that the existing curriculum does not offer the students the ability to develop soft skills and that systematic efforts should be put in place to improve this drawback.

Among the soft skills, the ability to work in multidisciplinary teams received particular attention. The implementation of SDGs is a complex issue and requires the joint contribution of different 
disciplines and stakeholders. It is, thus, more than necessary for RM graduates to understand the different "languages" and the diverse perspectives that other scientists and professionals bring to successfully collaborate with them. Similarly, the participants also mentioned the importance of RM graduates adopting and following a standard of professional behaviour and code of ethics. Their views were primarily based on the argument that SD itself establishes an ethical system. However, it was referred that even though ethical issues related to SD can be taught, ethics is more or less up to the individual.

The role of innovation and Lifelong Learning (LLL) for the implementation of SDGs by the RM sector was also discussed. All the participants underlined the significance of innovation as a means to accelerate the implementation of SD principles. In regards to LLL, the participants underlined its necessity especially in educating the employees of the sector and exposing the wider public in the principles of SD. Many RM engineers, aged more than 35 years, do not have the knowledge and competencies required to implement the principles of SD in their workspaces. LLL could, therefore, help to remove the obstacles to SD. Participants from academia and professionals proposed that RM schools should undertake initiatives and prepare appropriate programs in this direction.

\subsubsection{The role of the external environment}

The focus group drew attention to the role of the external environment. Two issues were examined, namely the importance of policies and legislation and the importance of the commitment of the RM sector to the principles of SD as a means for incorporating the SDGs in the curriculum of the RM schools/departments.

Concerning legislation and SD policies, all the participants stated that they play an important role. The participants from academia, in particular, indicated that (at least) some curriculum courses are reorganised in an attempt to incorporate recent developments in environmental policies and regulations. From this viewpoint, it becomes evident that education and exposure to SD policies may act as a catalyst for promoting SD principles in RM graduates. Focusing on the commitment of the RM sector to the principles of SD, all the participants were adamant that the implementation of SD principles is a must for the RM sector. Consequently, and in order to ensure the sustainable development of the sector, RM engineers with comprehensive knowledge of sustainability principles, related soft skills, innovative thinking and strong professional behaviour play a pivotal role.

\subsection{FCM analysis}

At the second part of the interviews, the stakeholder representatives identified, in total, fifteen components of the RM whole value chain SDGseducation-innovation system, as follows:

- SDGs curriculum enhancement (F1)

- Courses content and teaching methods (F2)

- Increase in employment opportunities (F3)

- SDGs-related legislation and policies (F4)

- Inclusion of SDGs examples in many courses (F5)

- SDGs separate courses (F6)

- Implementation of SDGs by the RM sector (F7)

- Industry-HEIs collaboration (UBC) (F8)

- Ethics code development (F9)

- Faculty knowledge about SDGs (F10)

- Soft skills (F11)

- Internship (F12)

- Lifelong learning (LLL) (F13)

- Social pressure for SD (F14)

- Social acceptance of RM sector (F15)

The concepts cover a wide range of issues from teaching approaches and curriculum structure to social pressure for SD and social acceptance of the RM sector. After having identified the components of the systems, the participants were asked to define the causal links between the components and to assess the strength of these causal relationships, in the interval $[-1,1]$. In particular, the experts were asked to assign the strength of influence of concept $C_{i}$ on concept $C_{j}$ using the following form "the strength of influence of concept $C_{i}$ on concept $C_{j}$ is T \{influence\}", where the variable T\{influence\} declares the causal inter-relationships among employing a fuzzy linguistic variable with nine linguistic levels, as follows: negatively very strong, negatively strong, negatively medium, negatively weak, zero, positively weak, positively medium, positively strong, positively very strong.

Both the causal links and the weights were defined after deliberation by consensus. The FCM as agreed by the participating Greek stakeholders is illustrated in Fig. 1, created with the Pajek software (http://mrvar.fdv.uni-lj.si/pajek/). The matrix of the 


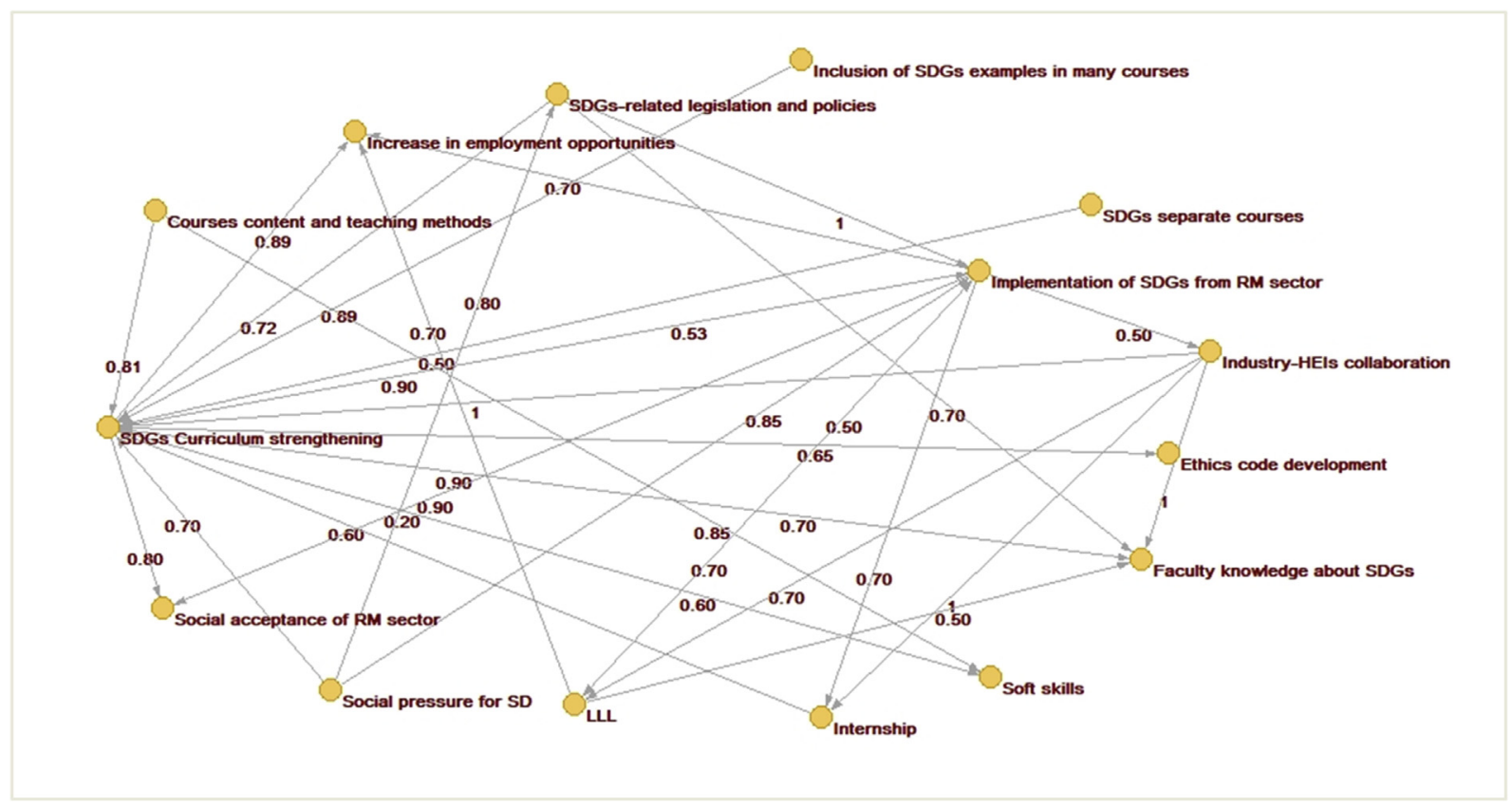

Fig. 1. The FCM of the EnAct - SDGs Greek stakeholder representatives.

weight of interconnections (i.e. adjacency matrix) is presented in Table S1 of the Supplement.

According to the participating stakeholders, the enhanced incorporation and strengthening of the SDGs in RM curricula is affected, in order of importance, by the collaboration of HEI and Industry (UBC), the implementation of the SDGs by the RM industry, the knowledge of the academic staff about the SDGs, the use of SDGs' examples in as many courses as possible, the content of the courses and the teaching methods, the existence of SDGs related policies and legislations, the social pressure for SD, the internships, the existence of a stand-alone SD course and the development of soft skills to the students. Moreover, the participants believe that the strengthening of the SDGs in RM curricula has a positive impact on the employment perspectives of RM graduates, the social acceptance of the RM sector, the knowledge of the academic staff about the SDGs, the development of ethics code and the implementation of the SDGs by the RM industry.

Selected graph theory indices obtained from the Greek stakeholders FCM developed within the EnAct Project, Greek FCM, are given in Table S2 of the Supplement, while the most central concepts are presented in Table 1.

The most central variable of the Greek FCM is as expected - the SDGs curriculum strengthening with a centrality of 11.4. The other five most central

Table 1. The most central concepts in the Greek FCM.

\begin{tabular}{llll}
\hline Concepts & Outdegree & Indegree & Centrality \\
\hline SDGs curriculum strengthening & 4.17 & 7.22 & 11.39 \\
Courses content and teaching methods & 1.66 & 0.00 & 2.66 \\
Increase in employment opportunities & 0.00 & 2.29 & 2.29 \\
SDGs related legislation and policies & 2.42 & 0.80 & 0.00 \\
Inclusion of SDGs examples in many courses & 0.89 & 0.00 & 3.22 \\
SDGs separate courses & 0.50 & 2.88 & 0.89 \\
Implementation of SDGs by the RM sector & 4.40 & 0.50 & 7.28 \\
Industry-HEIs collaboration & 3.70 & 0.65 & 4.20 \\
Ethics code development & 0.00 & 2.90 & 0.65 \\
Faculty knowledge about SDGs & 0.90 & 1.45 & 3.80 \\
Soft skills & 0.20 & 1.70 & 1.65 \\
Internship & 0.60 & 1.40 & 2.30 \\
Lifelong learning (LLL) & 1.70 & 0.00 & 3.10 \\
Social pressure for SD & 2.35 & 1.70 & 2.35 \\
Social acceptance of RM sector & 0.00 & 1.70 \\
\hline
\end{tabular}


concepts are (in order of significance) the implementation of SDGs by RM sector, the industry-HEIs collaboration, the faculty knowledge about SDGs, the SDGs related legislation and policies and the lifelong learning (LLL). The most influencing factors, as shown by the outdegree values, are (in order of significance) the implementation of SDGs by RM sector, the SDGs curriculum strengthening and the industry-HEIs collaboration.

A number of simulations were then conducted focusing on the transient behaviour of the system during the iteration steps by means of the FCM tool, a software that works in Matlab environment [83]. In this process, known as clamping by [58], critical variables are gradually increased or decreased and the values of the final state are compared to the steady-state vector [84]. In all simulations, the initial values used for the concept under investigation were sequentially set to $0,0.25,0.5,0.75$ and 1 , representing possible situations, i.e. from zero to the highest possible level. The simulation process took place for the most important factors and more specifically for three external (i.e. industry-HEIs collaboration, implementation of SDGs by the RM sector and SDGs related legislation and policies) and two internal university environment factors (i.e. faculty knowledge about SDGs and inclusion of SDGs examples in many courses).

The results of the simulations are presented in Figs. 2-6 and discussed hereinafter.

As illustrated in Fig. 2, clamping industry-HEIs collaboration has practically no effect on the SDGs curriculum strengthening, as well as on the rest of the parameters except for the internship, LLL and faculty knowledge about SDGs. Specifically, clamping the industry-HEIs collaboration to a low up to a medium level has a negative and significant effect (i.e. the relative change is $5 \%$ and $15 \%$ ), on internship, LLL and faculty knowledge about SDGs, whereas clamping the same factor to the highest level, has a positive effect mainly on internship and LLL.

The implementation of SDGs by the RM sector factor has a more notable effect on five factors of the system, namely the internship, LLL, industry-HEIs collaboration, social acceptance of the RM sector and increase in employment opportunities, as shown in Fig. 3. In all states but the highest level, the implementation of SDGs by the RM sector has a negative influence on the above-mentioned factors. More specifically, when the implementation of SDGs by the RM sector is set to the lowest level (i.e. the RM sector does not adopt the SDGs), the final stage values are reduced by around $20 \%$ or more, compared to those recorded when the implementation of SDGs by the RM sector is set to the highest level (i.e. the RM sector fully adopts the SDGs). Hence, although the direct impact on the SDGs curriculum strengthening is relatively low, the reduction in the implementation of SDGs by the $\mathrm{RM}$ sector has a significant and negative effect on critical factors of the RM whole value chain SDGseducation-innovation eco-system that could jeopardise its sustainability.

As regards the SDGs related legislation and policies (Fig. 4), the relative changes are markedly higher only for the implementation of SDGs by the RM sector and the faculty knowledge about SDGs. The analysis shows that not only the interest of the RM industry but also the interest of the academic personnel are affected by the existence (and of course the implementation) of the SD legislative

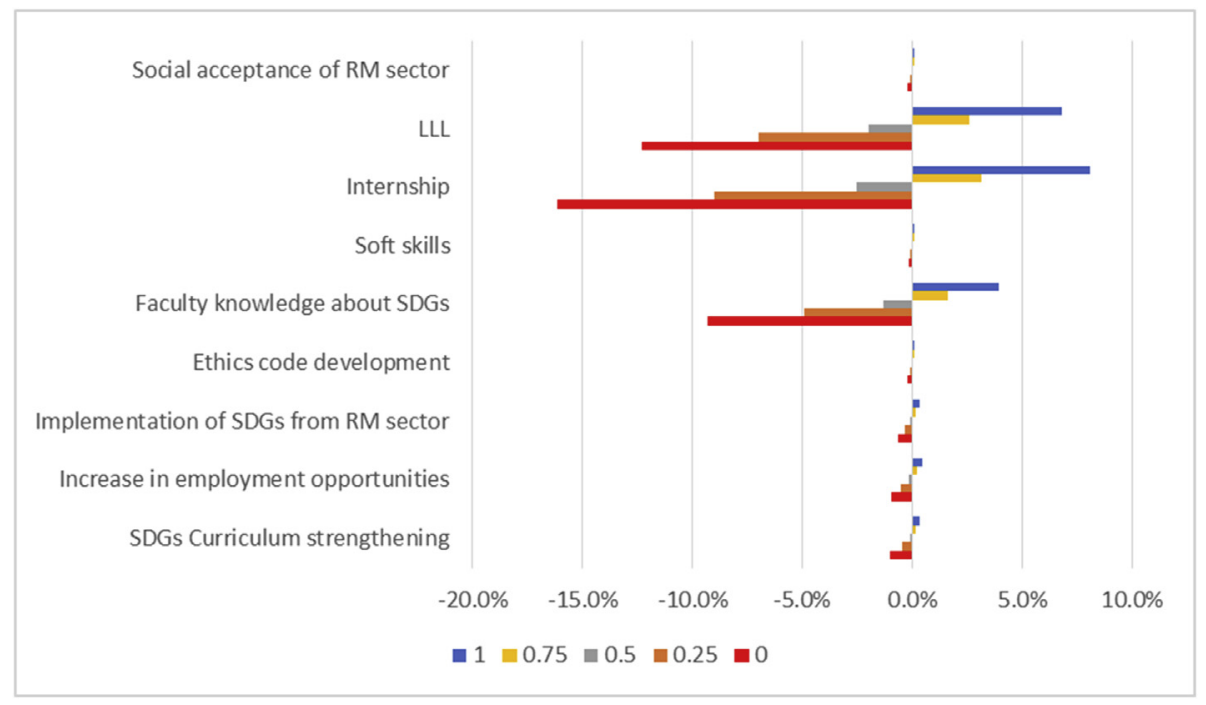

Fig. 2. The effect of industry-HEIs collaboration on the other concepts of the FCM. 


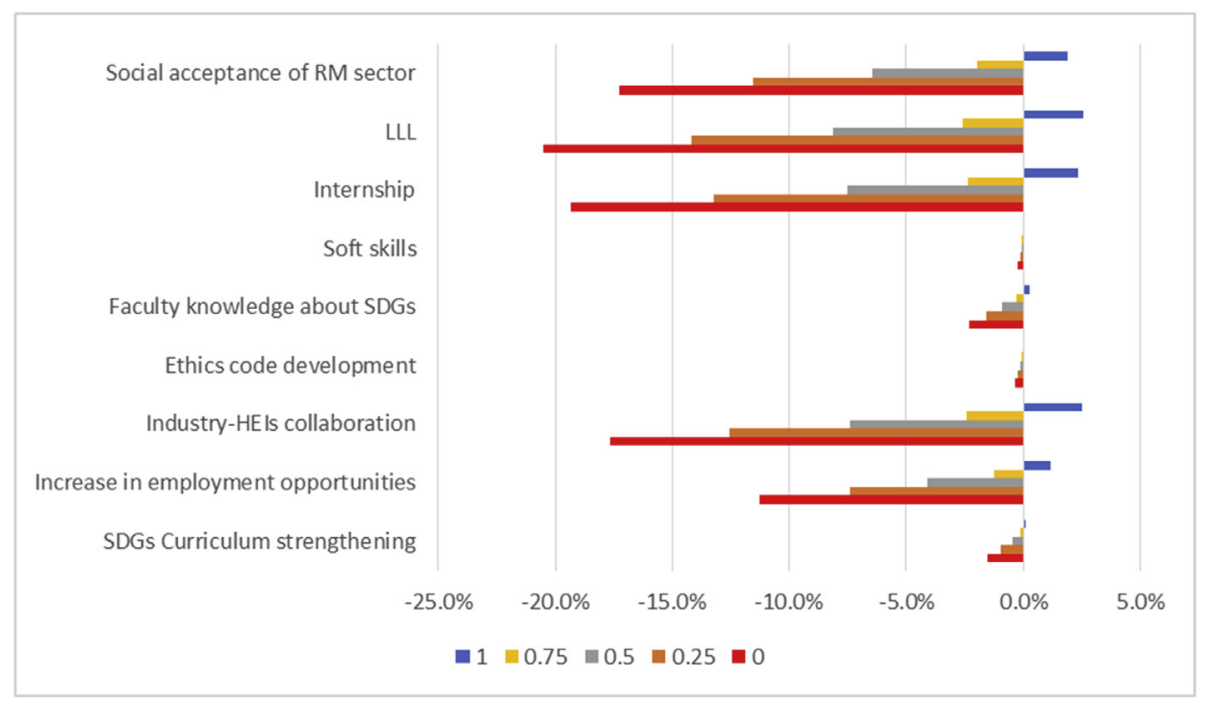

Fig. 3. The effect of Implementation of SDGs by the RM sector on the other concepts of the FCM.

framework. The impact of this parameter on the other factors, including the SDGs curriculum strengthening is negligible. Therefore, and despite the fact that the impact of this factor on the SDGs curriculum strengthening is insignificant, the application of SDGs related legislation and policies deserves certain attention because the other affected factors are of high importance.

According to Figs. 5 and 6, the effect of the internal university environment factors on the SDGs curriculum strengthening as well as on the other parameters is not significant. More specifically, in both cases, the relative change on the SDGs curriculum strengthening between the lowest and the highest clamping levels is around $1 \%$, which is considered as the same as the impact of the other factors tested.

As a general remark, it could be argued that the impact of the factors associated with the SDGs Curriculum strengthening is not significant when considering ceteris paribus changes. However, the results may be remarkable when examining "worstcase" scenarios, i.e. situations where more than one critical factors are unfavourable. For instance, setting simultaneously the most important external and internal university environment factors to a low level (e.g. less than 0.25) results in relative changes of around $15 \%$ for the SDGs curriculum strengthening and up to $40 \%$ for the internship and the LLL.

\section{Conclusions}

The present paper aims to identify the educational needs and challenges faced by RM faculties for incorporating the SDGs into their curricula and the impact of the various external and internal factors in this procedure. The analysis is based on the opinions and beliefs of key stakeholders from the Greek academia, industry, and professionals, using information collected through semi-structured group discussions and developing the FCM of the RM whole value chain SDGs-education-innovation system within the EnAct-SDGs project.

All the stakeholders share the view that it is quite important to integrate sustainability principles into the RM engineering curricula and this should be considered a priority in the educational process. In particular, the representatives from the industry and the professionals highlighted the significance of SD principles for the RM sector and pointed out that exposure and use of the SD principles is a prerequisite for RM engineers. The analysis indicated that this has also a direct effect on students' satisfaction. However, it was argued that regarding the existing curriculum of the Greek RM Engineering School examined, School of Mining and Metallurgical Engineering, NTUA, only a few courses provide the basics of SD principles, so far. The academic participants recognised that although theoretical and technical knowledge remains an important asset for RM engineers, the need to strengthen the knowledge offered in the RM faculties with regards to sustainability and soft skills is undisputed. Therefore, the critical challenge faced nowadays by the RM Engineering departments in Eastern and Southeastern Europe, Greece included, is to ensure the right balance in their RM study programs.

Regarding the teaching approaches used to enhance RM students' skills towards the achievement of the SDGs, the stakeholders generally agree 


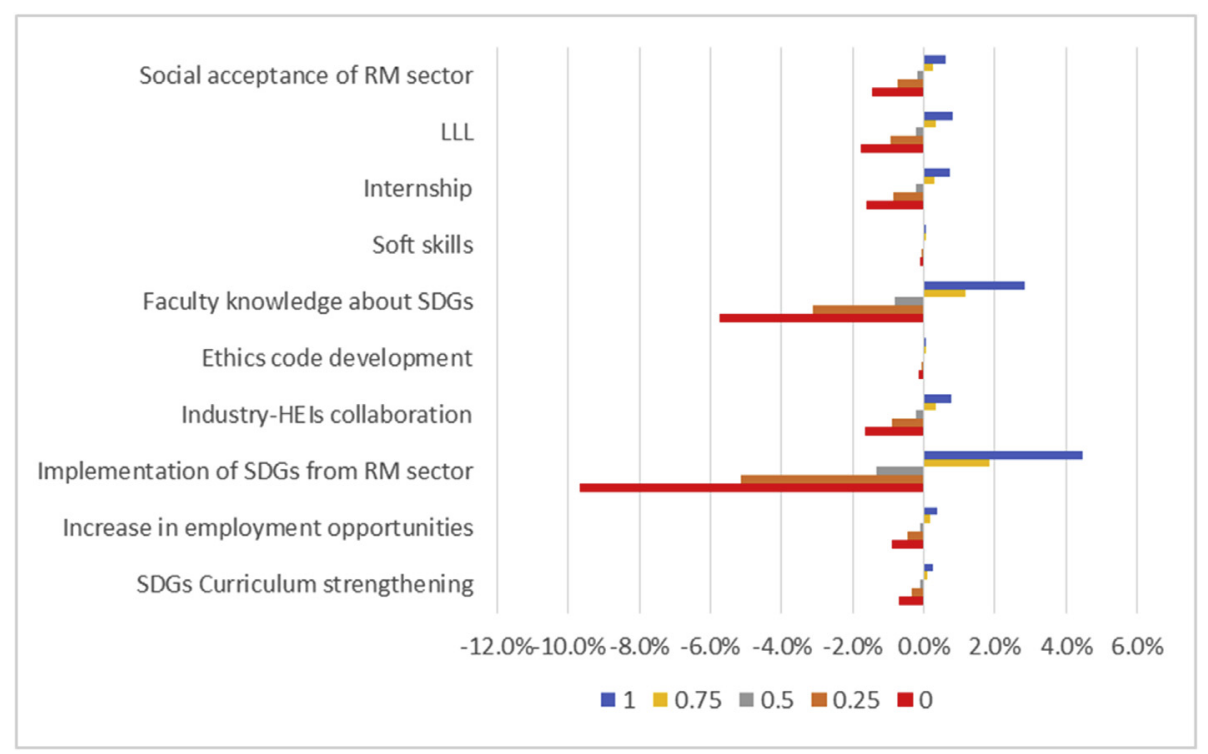

Fig. 4. The effect of SDGs-related legislation and policies on the other concepts of the FCM.

that SD principles should be actively incorporated and promoted through as many technical courses as possible. Nevertheless, it was noted that a compulsory course that would introduce the role of SD and the basics of the SDGs would also contribute towards this direction. As far as the teaching methods are concerned, the academic staff participating in the interviews and the design of the FCM suggested that the most appropriate methods for sustainability teaching are, as follows: running a student virtual mine, conducting a cost-benefit analysis, linking the applications to industrial practice and reviewing scientific articles related to SD. These teaching methods can be used to improve the knowledge and awareness of students about social, environmental, and economic sustainability through the application of sustainable engineering practices in an interdisciplinary framework. These methods could also contribute to knowledge, skills, and personal development in the areas of theoretical and technical knowledge, soft skills and decision-making techniques. In the same direction, it was mutually agreed that the internship is important not only to the career path of RM engineering students but also - and mainly to - the implementation of SDGs by the RM sector and to the enhancement of

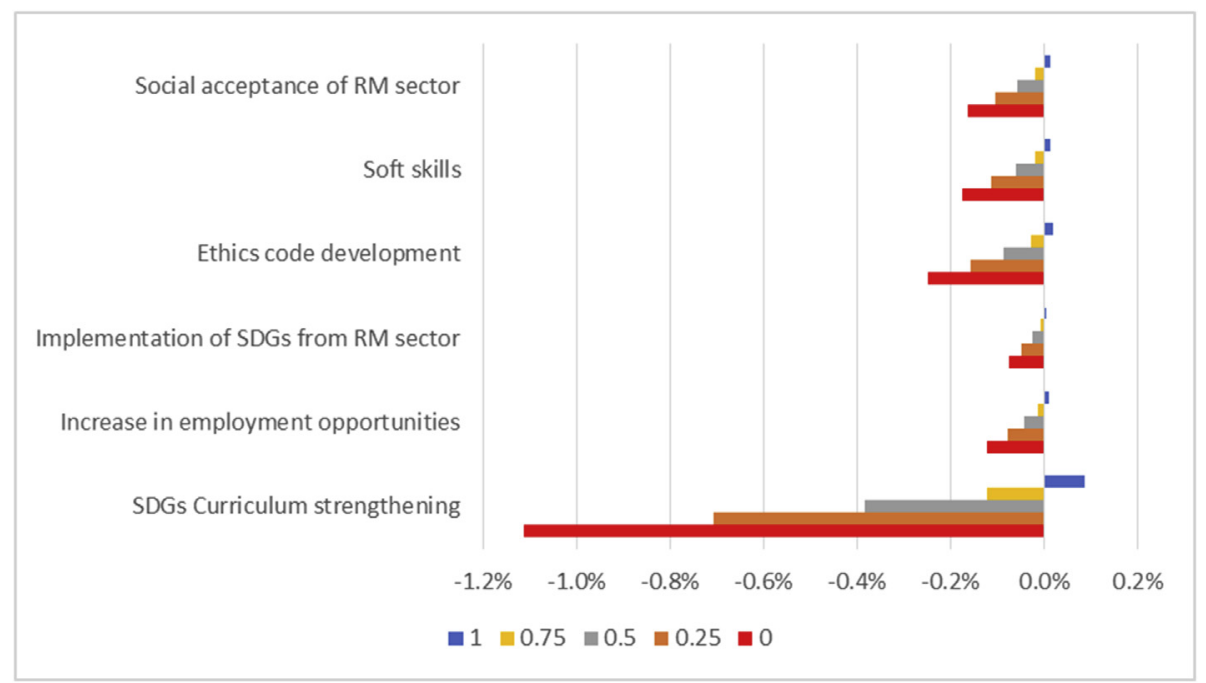

Fig. 5. The effect of faculty knowledge about SDGs on the other concepts of the FCM. 


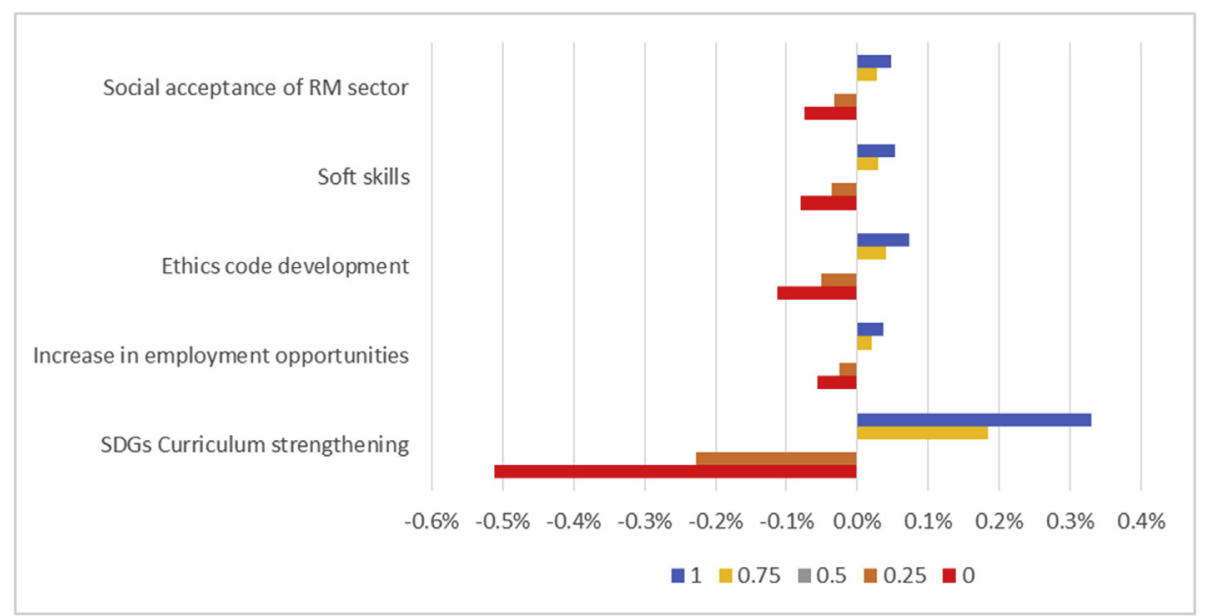

Fig. 6. The effect of inclusion of SDGs examples in many courses on the other concepts of the FCM.

cooperation between academia and industry. The students, through internships, have a first view on how the RM sector deals with the SDGs and are given the opportunity to start considering their role, as engineers, in improving the sustainability performance of the extractive industry. Further, all the stakeholders considered soft skills fundamentally important for RM engineers since they provide them with the ability to comprehend and interpret the concept of SD and, therefore, play a critical role in the SDGs implementation. Finally, all the participants stressed the importance of LLL especially when taking into account the rapid changes in technology and the future challenges to be faced by the RM sector, noting that LLL could help RM graduates to remove the obstacles towards SD.

The FCM approach offered the means to explore the fifteen factors identified by the stakeholders in the RM whole value chain SDGs-education-innovation system and the interactions between them. The FCM modelling also provided the tool to elucidate the role of the factors interacting in the above RM system. More specifically, the dynamic evolution of the system using the clamping process showed that ceteris paribus changes do not result in significant alterations in the SDGs curriculum strengthening. Nevertheless, if more than one critical factors are simultaneously found in unfavourable conditions then the influence on the SDGs curriculum strengthening could be important. From a policy perspective, it was concluded that external university environment factors, such as the industry-HEIs collaboration, the implementation of SDGs by the RM sector and the SDGs-related legislation and policies may significantly affect other important factors of the system like the LLL, the internship and very importantly the social acceptance of the RM sector and the increase in employment opportunities.

To the authors' best knowledge, this is the first attempt to apply the FCM method to this topic indicating the need for further research into the interacting factors impacting the RM whole value chain SDGs-education-innovation system. The model presented in this article reflects the particular characteristics and opinions of the stakeholders of the RM sector in Greece and was developed by participants from academia, students, industry and professionals. In this direction, it is suggested to expand the number of focus groups from different stakeholders, and countries and create separate FCMs per group as a means to further evaluate the factors impacting the incorporation of the Sustainable Development Goals into Raw Materials Engineering Curricula.

\section{Conflicts of interest}

None declared.

\section{Ethical statement}

Authors state that the research was conducted according to ethical standards.

\section{Funding body}

This research was funded by the EIT RawMaterials in the context of the EnAct-SDGs project, No. 19258. 


\section{Acknowledgments}

Research data presented in this article were obtained within the EnAct-SDGs project, No. 19258 funded by EIT RawMaterials, which is gratefully acknowledged.

\section{Appendix I.}

Questions posed during the discussion about the educational needs, i.e. the areas that need to be enhanced in the curriculum of RM schools/departments to strengthen the skills and competencies of RM graduates and successfully achieve the implementation of SDGs by the RM sector.

Q1. How important (and why) is it to integrate sustainability thinking into the traditional engineering curriculum of the RM schools/ departments?

Q2. Should SDGs be actively incorporated and promoted through all (or as many as possible) the courses of the curriculum (even purely engineering ones) or as a separate course on its own? What are the pros and cons of each approach?

Q3. How important (and why) is the commitment of the RM sector to the principles of Sustainable Development for incorporating the SDGs in the curriculum of the RM schools/departments?

Q4. How important (and why) is the role of policies and legislation for incorporating the SDGs in the curriculum of the RM schools/departments (e.g. do the RM schools consider the evolution of

environmental legislation/policy when preparing/updating their curricula?)

Q5. How important (and why) is it for RM graduates to have acquired soft skills (e.g. ability to communicate with competent authorities, local communities and other stakeholders, emotional intelligence, etc.) in the context of SDGs implementation?

Q6. Is the internship important (and why) for understanding better the role of SDGs for the RM sector?

Q7. Is the role of Life Long Learning (LLL) important (and why) for the implementation of SDGs by the RM sector?

Q8. How important (and why) is it for RM graduates to have the ability to work in multidisciplinary teams in the context of SDGs implementation?

Q9. Is it important (and why) to increase the creativity and ability of RM graduates to innovate towards achieving the implementation of SDGs by the RM sector?

Q10. How important (and why) is it for RM graduates to perform under a standard of professional behaviour and code of ethics for achieving the implementation of SDGs by the RM sector?

\section{Supplement}

Table S1. The adjacency matrix of the "RM whole value chain-SDGs-education-innovation" system, as developed by the participating Greek stakeholders.

\begin{tabular}{|c|c|c|c|c|c|c|c|c|c|c|c|c|c|c|c|}
\hline & F1 & F2 & F3 & F4 & F5 & F6 & F7 & F8 & F9 & F10 & F11 & F12 & F13 & F14 & F15 \\
\hline F1 & 0.00 & 0.00 & 0.89 & 0.00 & 0.00 & 0.00 & 0.53 & 0.00 & 0.65 & 0.70 & 0.60 & 0.00 & 0.00 & 0.00 & 0.80 \\
\hline F2 & 0.81 & 0.00 & 0.00 & 0.00 & 0.00 & 0.00 & 0.00 & 0.00 & 0.00 & 0.00 & 0.85 & 0.00 & 0.00 & 0.00 & 0.00 \\
\hline F3 & 0.00 & 0.00 & 0.00 & 0.00 & 0.00 & 0.00 & 0.00 & 0.00 & 0.00 & 0.00 & 0.00 & 0.00 & 0.00 & 0.00 & 0.00 \\
\hline F4 & 0.72 & 0.00 & 0.00 & 0.00 & 0.00 & 0.00 & 1.00 & 0.00 & 0.00 & 0.70 & 0.00 & 0.00 & 0.00 & 0.00 & 0.00 \\
\hline F5 & 0.89 & 0.00 & 0.00 & 0.00 & 0.00 & 0.00 & 0.00 & 0.00 & 0.00 & 0.00 & 0.00 & 0.00 & 0.00 & 0.00 & 0.00 \\
\hline F6 & 0.50 & 0.00 & 0.00 & 0.00 & 0.00 & 0.00 & 0.00 & 0.00 & 0.00 & 0.00 & 0.00 & 0.00 & 0.00 & 0.00 & 0.00 \\
\hline F7 & 0.90 & 0.00 & 0.70 & 0.00 & 0.00 & 0.00 & 0.00 & 0.50 & 0.00 & 0.00 & 0.00 & 0.70 & 0.70 & 0.00 & 0.90 \\
\hline F8 & 1.00 & 0.00 & 0.00 & 0.00 & 0.00 & 0.00 & 0.00 & 0.00 & 0.00 & 1.00 & 0.00 & 1.00 & 0.70 & 0.00 & 0.00 \\
\hline F9 & 0.00 & 0.00 & 0.00 & 0.00 & 0.00 & 0.00 & 0.00 & 0.00 & 0.00 & 0.00 & 0.00 & 0.00 & 0.00 & 0.00 & 0.00 \\
\hline F10 & 0.90 & 0.00 & 0.00 & 0.00 & 0.00 & 0.00 & 0.00 & 0.00 & 0.00 & 0.00 & 0.00 & 0.00 & 0.00 & 0.00 & 0.00 \\
\hline F11 & 0.20 & 0.00 & 0.00 & 0.00 & 0.00 & 0.00 & 0.00 & 0.00 & 0.00 & 0.00 & 0.00 & 0.00 & 0.00 & 0.00 & 0.00 \\
\hline F12 & 0.60 & 0.00 & 0.00 & 0.00 & 0.00 & 0.00 & 0.00 & 0.00 & 0.00 & 0.00 & 0.00 & 0.00 & 0.00 & 0.00 & 0.00 \\
\hline F13 & 0.00 & 0.00 & 0.70 & 0.00 & 0.00 & 0.00 & 0.50 & 0.00 & 0.00 & 0.50 & 0.00 & 0.00 & 0.00 & 0.00 & 0.00 \\
\hline F14 & 0.70 & 0.00 & 0.00 & 0.80 & 0.00 & 0.00 & 0.85 & 0.00 & 0.00 & 0.00 & 0.00 & 0.00 & 0.00 & 0.00 & 0.00 \\
\hline F15 & 0.00 & 0.00 & 0.00 & 0.00 & 0.00 & 0.00 & 0.00 & 0.00 & 0.00 & 0.00 & 0.00 & 0.00 & 0.00 & 0.00 & 0.00 \\
\hline
\end{tabular}

Table S2. Graph theory indices for the Greek FCM.

\begin{tabular}{lllllll}
\hline Density & Complexity & Total Nr. Factors & Total Nr. Connections & Nr. Transmitter & Nr. Receiver & Nr. Ordinary \\
\hline 0.142 & 0.75 & 15 & 32 & 4 & 3 & 8 \\
\hline
\end{tabular}




\section{References}

[1] United Nations. United Nations transforming our world: the 2030 Agenda for sustainable development. A/RES/70/1, vol. 16301. United Nations, Department of Economic and Social Affairs, Sustainable Development; 2015.

[2] Eisenmenger N, Pichler M, Krenmayr N, Noll D, Plank B, Schalmann E, et al. The Sustainable Development Goals prioritize economic growth over sustainable resource use: a critical reflection on the SDGs from a socio-ecological perspective. Sustain Sci 2020;15:1101-10. https://doi.org/ 10.1007/s11625-020-00813-x.

[3] Easterly W. The trouble with the sustainable development goals. Curr Hist 2015;114:322-4. https://doi.org/10.1525/ curh.2015.114.775.322.

[4] Gupta J, Vegelin C. Sustainable development goals and inclusive development. Int Environ Agreements Polit Law Econ 2016;16:433-48. https://doi.org/10.1007/s10784-0169323-z.

[5] Hartlieb P, Bordehore LJ, González-Barros MR y, Correia V, Vidovic J. A comprehensive skills catalogue for the raw materials sector and the structure of raw materials education worldwide. Min Technol 2020;129:82-94. https://doi.org/ 10.1080/25726668.2020.1770406.

[6] Swain RB. A critical analysis of the sustainable development goals. In: Leal Filho W, editor. Handbook of sustainability science and research. Cham: Springer International Publishing; 2018. p. 341-55. https://doi.org/10.1007/978-3-31963007-6_20.

[7] Swain RB, Yang-Wallentin F. Achieving sustainable development goals: predicaments and strategies. Int J Sustain Dev World Ecol 2020;27:96-106. https://doi.org/10.1080/ 13504509.2019.1692316.

[8] Biermann F, Kanie N, Kim RE. Global governance by goalsetting: the novel approach of the UN Sustainable Development Goals. Curr Opin Environ Sustain 2017;26-27:26-31. https://doi.org/10.1016/j.cosust.2017.01.010.

[9] Morton S, Pencheon D, Bickler G. The sustainable development goals provide an important framework for addressing dangerous climate change and achieving wider public health benefits. Publ Health 2019;174:65-8. https://doi.org/10.1016/ j.puhe.2019.05.018.

[10] Monteiro NBR, Silva EA da, Neto JMM. Sustainable development goals in mining. J Clean Prod 2019;228:509-20. https://doi.org/10.1016/j.jclepro.2019.04.332.

[11] United Nations Environment Programme. Mineral resource governance in the 21st century. United Nations; 2020.

[12] Mancini L, Sala S. Social impact assessment in the mining sector: review and comparison of indicators frameworks. Resour Pol 2018;57:98-111. https://doi.org/10.1016/ j.resourpol.2018.02.002.

[13] Sonesson C, Davidson G, Sachs L. Mapping mining to the sustainable development goals: a preliminary atlas. Undp Wef Ccsi 2016:77.

[14] Ivic A, Saviolidis NM, Johannsdottir L. Drivers of sustainability practices and contributions to sustainable development evident in sustainability reports of European mining companies. Dis Sustain 2021;2:17. https://doi.org/10.1007/ s43621-021-00025-y.

[15] Franks DM, Davis R, Bebbington AJ, Ali SH, Kemp D, Scurrah M. Conflict translates environmental and social risk into business costs. Proc Natl Acad Sci Unit States Am 2014; 111:7576-81. https://doi.org/10.1073/pnas.1405135111.

[16] Pacher C, Valakas G, Adam K. Raw materials curricula and sustainable development: assessment of curricula towards the achievement of Sustainable Development Goals. GAIA 2021;29:269-71. https://doi.org/10.14512/GAIA.29.4.13.

[17] UNESCO. Intergovernmental conference on environmental education. The Tbilisi Declaration 1977;1-8.

[18] United Nations. Agenda 21 United Nations conference on environment \& development. Reproduction 1992:351.
[19] UNESCO. UN decade of education for sustainable development (DESD 2005-2014): the first two years. Section for DESD coordination (ED/UNP/DESD), division for the Coordination of UN priorities in education. UNESCO; 2007.

[20] WFEO. Engineers and sustainable development. Tunis, Tunisia: World Federation of Engineering Organisations' Committee on Technology; 2002.

[21] UNESCO. Engineering: issues, challenges and opportunities for development. 2010.

[22] Byrne E, Desha C, Fitzpatrick J, Hargroves K. Engineering education for sustainable development: a review of international progress. 3rd International Symposium for Engineering Education; 2010. p. 42.

[23] Desha CJ, Hargroves K, Smith MH. Addressing the time lag dilemma in curriculum renewal towards engineering education for sustainable development. Int J Sustain High Educ 2009;10:184-99. https://doi.org/10.1108/14676370910949356.

[24] Kelly WE. Brief for GSRD-2016 update engineering education for sustainable development. 2016.

[25] Amashi R, Joshi G, Kandakatla R. The influence of sustainable development module on the values and beliefs of firstyear students in undergraduate engineering education. J Eng Edu Transform 2021;34. https://doi.org/10.16920/jeet/2021/ v34i0/157112.

[26] Desha C, Rowe D, Hargreaves D. A review of progress and opportunities to foster development of sustainability-related competencies in engineering education. Australas J Eng Educ 2019;24. https://doi.org/10.1080/22054952.2019.1696652.

[27] Duarte AJ, Malheiro B, Arno E, Perat I, Silva MF, FuentesDura $P$, et al. Engineering education for sustainable development: the European project semester approach. IEEE Trans Educ 2020;63. https://doi.org/10.1109/TE.2019.2926944.

[28] Guerra A. Integration of sustainability in engineering education: why is PBL an answer? Int J Sustain High Educ 2017; 18. https://doi.org/10.1108/IJSHE-02-2016-0022.

[29] Kamp L. Engineering education in sustainable development at delft university of technology. J Clean Prod 2006;14. https://doi.org/10.1016/j.jclepro.2005.11.036.

[30] Körfgen A, Förster K, Glatz I, Maier S, Becsi B, Meyer A, et al. It's a hit! Mapping Austrian research contributions to the sustainable development goals. Sustainability 2018;10. https://doi.org/10.3390/su10093295.

[31] Lucena J, Schneider J. Engineers, development, and engineering education: from national to sustainable community development. Eur J Eng Educ 2008;33. https://doi.org/ $10.1080 / 03043790802088368$.

[32] Manolis EN, Manoli EN. Raising awareness of the sustainable development goals through ecological projects in higher education. J Clean Prod 2021;279. https://doi.org/10.1016/ j.jclepro.2020.123614.

[33] Ortiz-Marcos I, Breuker V, Rodríguez-Rivero R, Kjellgren B, Dorel F, Toffolon M, et al. A framework of global competence for engineers: the need for a sustainable world. Sustainability 2020;12. https://doi.org/10.3390/su12229568.

[34] Ramirez-Mendoza RA, Morales-Menendez R, MelchorMartinez EM, Iqbal HMN, Parra-Arroyo L, VargasMartínez A, et al. Incorporating the sustainable development goals in engineering education. Int J Interact Des Manuf 2020;14. https://doi.org/10.1007/s12008-020-00661-0.

[35] Rampasso IS, Quelhas OLG, Anholon R, Pereira MB, Miranda JDA, Alvarenga WS. Engineering education for sustainable development: evaluation criteria for Brazilian context. Sustainability 2020;12. https://doi.org/10.3390/ SU12103947.

[36] Rivera FML, Hermosilla P, Delgadillo J, Echeverría D. The sustainable development goals (SDGs) as a basis for innovation skills for engineers in the industry 4.0 context. Sustainability 2020;12. https://doi.org/10.3390/su12166622.

[37] Sánchez-Carracedo F, Sureda B, Moreno-Pino FM, RomeroPortillo D. Education for Sustainable Development in Spanish engineering degrees. Case study. J Clean Prod 2021; 294. https://doi.org/10.1016/j.jclepro.2021.126322. 
[38] Sivapalan S, Clifford MJ, Speight S. Engineering education for sustainable development: using online learning to support the new paradigms. Australas J Eng Educ 2016;21. https://doi.org/10.1080/22054952.2017.1307592.

[39] Takala A, Korhonen-Yrjänheikki K. A decade of Finnish engineering education for sustainable development. Int J Sustain High Educ 2019;20. https://doi.org/10.1108/IJSHE-072018-0132.

[40] Thuesen C, Geraldi J. The global goals for sustainable development in engineering education. The Danish Network for Engineering Education; 2017.

[41] Mahamud-López MM, Menéndez-Aguado JM. Environmental engineering in mining engineering education. Eur J Eng Educ 2005;30:329-39. https://doi.org/10.1080/ 03043790500114490.

[42] Costa S, Scoble M. An interdisciplinary approach to integrating sustainability into mining engineering education and research. J Clean Prod 2006;14:366-73. https://doi.org/ 10.1016/j.jclepro.2004.01.011.

[43] Johnson A, Thorley U. A new vision for mining education first steps. IJESJP 2014;3. https://doi.org/10.24908/ ijesjp.v3i1.5223.

[44] Adach-Pawelus K, Gogolewska A, Górniak-Zimroz J, Kiełczawa B, Krupa-Kurzynowska J, Paszkowska G, et al. A new face of mining engineer-international curricula to sustainable development and green deal (A case study of the Wrocław university of science and technology). Sustainability 2021;13. https://doi.org/10.3390/su13031393.

[45] Boks C, Diehl JC. Integration of sustainability in regular courses: experiences in industrial design engineering. J Clean Prod 2006;14:932-9. https://doi.org/10.1016/ j.jclepro.2005.11.038.

[46] Lozano R, Peattie K. Assessing Cardiff University's curricula contribution to sustainable development using the STAUNCH(RTM) system. J Edu Sustain Dev 2011;5:115-28. https://doi.org/10.1177/097340821000500114.

[47] Shields D, Verga F, Andrea Blengini G. Incorporating sustainability in engineering education. Int J Sustain High Educ 2014;15:390-403. https://doi.org/10.1108/IJSHE-02-2013-0014.

[48] Didham RJ, Ofei-Manu P. Facilitating collaborative partnerships in education policy research: a case of multi-stakeholder, Co-investigation for monitoring and evaluation of education for sustainable development. Sustainability 2020; 12. https://doi.org/10.3390/su12072787.

[49] Senge P, Smith B, Kruschwitz N, Schley S. The necessary revolution. How individuals and organizations are working together. The necessary revolution. How individuals and organizations are working together to create a sustainable world. 2008. p. 276-80.

[50] Carlsen B, Glenton C. What about N? A methodological study of sample-size reporting in focus group studies. BMC Med Res Methodol 2011;11. https://doi.org/10.1186/14712288-11-26. 26-26.

[51] Kitzinger J. Qualitative Research : introducing focus groups. Br Med J 1995;302:299-302.

[52] Krueger RA, Casey MA. Focus groups: a practical guide for applied research. 5th ed. Focus Groups: A Practical Guide for Applied Research; 2015.

[53] Sogunro OA. Motivating factors for adult learners in higher education. Int J High Educ 2015;4:22-37.

[54] Lubicz-Nawrocka TM. Students as partners in learning and teaching: the benefits of co-creation of the curriculum. Int J Students Partners 2018;2:47-63. https://doi.org/10.15173/ ijsap.v2i1.3207.

[55] Mulder KF, Jansen L. Integrating sustainable development in engineering education-reshaping university education by organizational learning. In: Holmberg J, Samuelsson BE, editors. Drivers and barriers for implementing sustainable development in higher education. Unesco; 2007. p. 69-75.

[56] Collins K, Davies JW. Feedback through student essay competitions: what makes a good engineering lecturer? Eng Edu 2009;4:8-15.
[57] United Nations. Proposal for a global action programme on education for sustainable development as follow-up to the United Nations decade of education for sustainable development (DESD) after 2014. 2013.

[58] Kosko B. Fuzzy cognitive maps. Int J Man Mach Stud 1986;24: 65-75. https://doi.org/10.1016/S0020-7373(86)80040-2.

[59] van Vliet M, Kok K, Veldkamp T. Linking stakeholders and modellers in scenario studies: the use of Fuzzy Cognitive Maps as a communication and learning tool. Futures 2010;42: 1-14. https://doi.org/10.1016/j.futures.2009.08.005.

[60] Chatterjee D, Dhaigude AS. An integrated fuzzy cognitive map approach in modelling factors of management quality in banking performance. Global Bus Rev 2020;21:763-79. https://doi.org/10.1177/0972150918778964.

[61] Engome Tchupo D, Kim JH, Macht GA. Fuzzy cognitive maps (FCMs) for the analysis of team communication. Appl Ergon 2020;83:102979. https://doi.org/10.1016/ j.apergo.2019.102979.

[62] Felix G, Nápoles G, Falcon R, Froelich W, Vanhoof K, Bello R. A review on methods and software for fuzzy cognitive maps. Artif Intell Rev 2019;52:1707-37. https://doi.org/10.1007/ s10462-017-9575-1.

[63] Giordano R, Passarella G, Uricchio VF, Vurro M. Fuzzy cognitive maps for issue identification in a water resources conflict resolution system. Phys Chem Earth, Parts A/B/C 2005;30:463-9. https://doi.org/10.1016/j.pce.2005.06.012.

[64] Henly-Shepard S, Gray SA, Cox LJ. The use of participatory modeling to promote social learning and facilitate community disaster planning. Environ Sci Pol 2015;45:109-22. https://doi.org/10.1016/j.envsci.2014.10.004.

[65] Jetter AJ, Kok K. Fuzzy Cognitive Maps for futures studies-a methodological assessment of concepts and methods. Futures 2014;61:45-57. https://doi.org/10.1016/ j.futures.2014.05.002.

[66] Kontogianni A, Tourkolias C, Papageorgiou EI. Revealing market adaptation to a low carbon transport economy: tales of hydrogen futures as perceived by fuzzy cognitive mapping. Int J Hydrogen Energy 2013;38:709-22. https://doi.org/ 10.1016/j.ijhydene.2012.10.101.

[67] Misthos L-M, Messaris G, Damigos D, Menegaki M. Exploring the perceived intrusion of mining into the landscape using the fuzzy cognitive mapping approach. Ecol Eng 2017;101:60-74. https://doi.org/10.1016/j.ecoleng.2017.01.015.

[68] Özesmi U, Özesmi S. A participatory approach to ecosystem conservation: fuzzy cognitive maps and stakeholder group Analysis in Uluabat lake, Turkey. Environ Manag 2003;31: 518-31. https://doi.org/10.1007/s00267-002-2841-1.

[69] Papageorgiou E, Kontogianni A. Using fuzzy cognitive mapping in environmental decision making and management: a methodological primer and an application. In: Young SS, Silvern SE, editors. International perspectives on global environmental change. Rijeka: IntechOpen; 2012. https://doi.org/10.5772/29375.

[70] Cole JR, Persichitte KA. Fuzzy cognitive mapping: applications in education. Int J Intell Syst 2000;15:1-25. https:// doi.org/10.1002/(SICI)1098-111X(200001)15:1<1::AIDINT1>3.0.CO;2-V.

[71] Laureano-Cruces AL, Ramírez-Rodríguez J, TeránGilmore A. Evaluation of the teaching-learning process with fuzzy cognitive maps. In: Lemaître C, Reyes CA, González JA, editors. Advances in artificial intelligence IBERAMIA 2004. Berlin, Heidelberg: Springer Berlin Heidelberg; 2004. p. 922-31.

[72] Pacheco R, Carlson R, Martins-Pacheco LH. Engineering education assessment system using fuzzy cognitive Maps. Salt Lake City, Utah: ASEE Conferences; 2004. https:// doi.org/10.18260/1-2-13759.

[73] Tsadiras A, Stamatis D. Decisions on networked learning based on fuzzy cognitive Maps. 2008.

[74] Yesil E, Ozturk C, Dodurka MF, Sahin A. Control engineering education critical success factors modeling via Fuzzy Cognitive Maps. In: 2013 12th International conference on information technology based higher education and training. 
ITHET; 2013. p. 1-8. https://doi.org/10.1109/ ITHET.2013.6671061.

[75] Gordaliza JAR, Flórez REV. Using fuzzy cognitive Maps to support complex environmental issues learning. 2013.

[76] Dias SB, Hadjileontiadou SJ, Hadjileontiadis LJ, Diniz JA. Fuzzy cognitive mapping of LMS users' Quality of Interaction within higher education blended-learning environment. Expert Syst Appl 2015;42:7399-423. https://doi.org/10.1016/ j.eswa.2015.05.048.

[77] Mourhir A, Kissani I. Foundation courses' soft skills evaluation using fuzzy cognitive maps. In: 2020 IEEE global engineering education conference (EDUCON); 2020. p. 308-14. https://doi.org/10.1109/EDUCON45650.2020.9125133.

[78] Eden C, Ackermann F, Cropper S. The analysis of cause maps. J Manag Stud 1992;29:309-24. https://doi.org/10.1111/ j.1467-6486.1992.tb00667.x.

[79] Özesmi U, Özesmi SL. Ecological models based on people's knowledge: a multi-step fuzzy cognitive mapping approach. Ecol Model 2004;176:43-64. https://doi.org/10.1016/j.eco lmodel.2003.10.027.
[80] Kosko B. Hidden patterns in combined and adaptive knowledge networks. Int J Approx Reason 1988;2:377-93. https://doi.org/10.1016/0888-613X(88)90111-9.

[81] Stylios CD, Groumpos PP. Mathematical formulation of fuzzy cognitive maps. In: Proceedings of the 7th mediterranean conference on control and automation; 1999.

[82] Komnitsas K. Social license to operate in mining: present views and future trends. Resources 2020;9. https://doi.org/ 10.3390/resources9060079.

[83] Papaioannou M, Neocleous C, Sofokleous A, Mateou N, Andreou A, Schizas CN. A generic tool for building fuzzy cognitive map systems. In: Papadopoulos H, Andreou AS, Bramer $M$, editors. Artificial intelligence applications and innovations. Berlin, Heidelberg: Springer Berlin Heidelberg; 2010. p. 45-52.

[84] Vasslides JM, Jensen OP. Fuzzy cognitive mapping in support of integrated ecosystem assessments: developing a shared conceptual model among stakeholders. J Environ Manag 2016;166:348-56. https://doi.org/10.1016/j.jenv man.2015.10.038. 